\title{
COMPREHENSIVE ECO-ENVIRONMENTAL IMPACT ASSESSMENT OF URBAN PLANNING BASED ON PRESSURE- STATE-RESPONSE MODEL
}

\author{
LIU, L. ${ }^{1,2}-$ ZHANG, Q. ${ }^{1,2^{*}}-$ WANG, C. L. ${ }^{1}-$ ZHANG, K. ${ }^{1}-$ ZHANG, X. ${ }^{1}$ \\ ${ }^{1}$ School of Art and Design of Zheng Zhou University of Light Industry, Zhengzhou 450002, \\ China \\ ${ }^{2}$ Henan Cultural Industry Development Research Base, Zhengzhou 450002, China \\ *Corresponding author \\ e-mail:27412397@qq.com
}

(Received $7^{\text {th }}$ Jun 2019; accepted $10^{\text {th }}$ Oct 2019)

\begin{abstract}
Considering the irreversible impacts of urban master plan on the eco-environment, the specific impacts must be evaluated in a comprehensive manner before preparing the plan. As a result, this paper studies the impacts of urban planning on eco-environment, sets up an assessment system for it based on the pressure-state-response (PSR) model, and applies the system to assess the eco-environment before and after the implementation of an urban master plan. The evaluation results show that the medium to longterm urban master plan promoted the eco-environment of the city. The research results shed new light on the eco-environmental impact assessment of urban master plans.
\end{abstract}

Keywords: urban planning, eco-environmental impact assessment, pressure-state-response (PSR) model, analytic hierarchy process (AHP), eco-environmental pressure

\section{Introduction}

In recent years, following the rapid development of China's urban economic level, the urbanization process has continued to advance (Wang et al., 2008). The extensive economic development model with high resource consumption brings not only the rapid urban development, but also "urban diseases" such as resource wasting, population expansion, and environmental damage (Crainic et al., 2009). All these affect the city's sustainable development, which will inevitably lead to irreversible problems for the city if not valued (Mancini et al., 2010; Liu et al., 2011). Therefore, it is necessary to design a master plan of urban land use and resource allocation for the healthy, orderly and harmonious development of the city.

Eco-environmental impact assessment was first proposed by American scholars in 1969, accompanied by an increasing environmental problem (Elena et al., 2008). After 40 years of development, it has been further verified that an urban master plan must consider its impact on the eco-environment under the condition of not destroying and improving the eco-environment (Pang et al., 2015). Only the environmentally friendly urban planning can ensure the sustainable development of the city, provide long-term benefits for environmental protection and the city, and further promote the decisionmaking system for environmental protection (Seenivasaperumal et al., 2010). For this, a study on comprehensive impact assessment of urban planning on eco-environment should be conducted, which not only helps the public to obtain effective information about the environmental impact of urban planning, but also enables government departments to realize the top-priority environmental indicators needed in plan implementation (Fitzpatrick et al., 2008). 
Over the years, China has attached more importance to environmental protection, and its research results on environmental impact assessment have become increasingly abundant (Shiojiri et al., 2010; Muthu et al., 2010). However, environmental impact assessment is mostly limited to engineering construction, and the research on ecoenvironmental impact assessment of urban master plan is still at the exploratory stage (Maj, 2015; Boulay et al., 2015). Thus, in order to ensure the coordinated and sustainable development of the overall city, the eco-environment should be improved in a scientific, orderly, efficient and reasonable manner, which can truly alleviate the pressure of eco-environment in urban planning (Zhou et al., 2013).

Therefore, this paper firstly introduces the connotation of PSR model. Based on this, an eco-environment evaluation system under the impact of urban planning was constructed. Then, the author proposed eco-environment improvement measures through comprehensive evaluation of the eco-environment of one city. The research results demonstrate feasibility of the comprehensive eco-environment impact assessment in urban master plan for the sustainable and harmonious development of cities, and also the objectivity and feasibility of the PSR model.

\section{Materials and methods}

The eco-environmental impact assessment of urban planning means to analyse and evaluate the impacts of the eco-environment and its ecosystems after urban planning of the structure, layout and land use, and then propose measures to mitigate the adverse effects (Wolfslehner and Vacik et al., 2008). The impact assessment system of urban planning on eco-environment is shown in Figure 1.

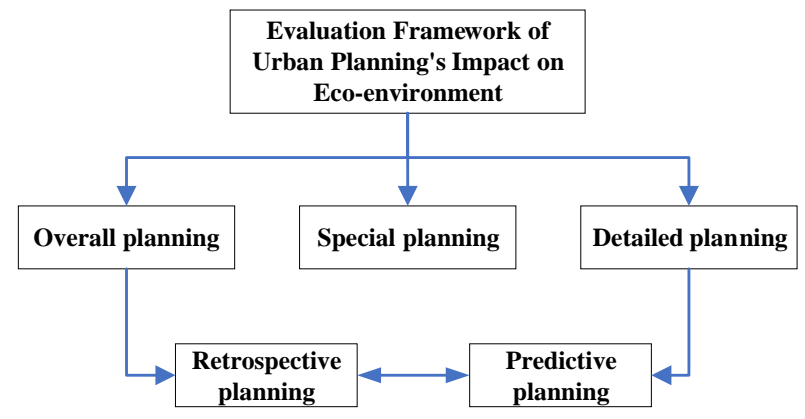

Figure 1. Urban planning impact assessment system on eco-environment

It should be noted that due to the different eco-environment conditions in different cities, the water environment, soil, plant diversity, natural disasters, etc. must be selected according to the environmental characteristics.

\section{Pressure-state-response model}

The PSR model is used for comprehensive assessment of eco-environmental impacts (Korol et al., 2016). It aims to construct one assessment system in three aspects: what the problems are, why the problems happen, and how to deal with these problems. Figure 2 shows the framework of the PSR model. 


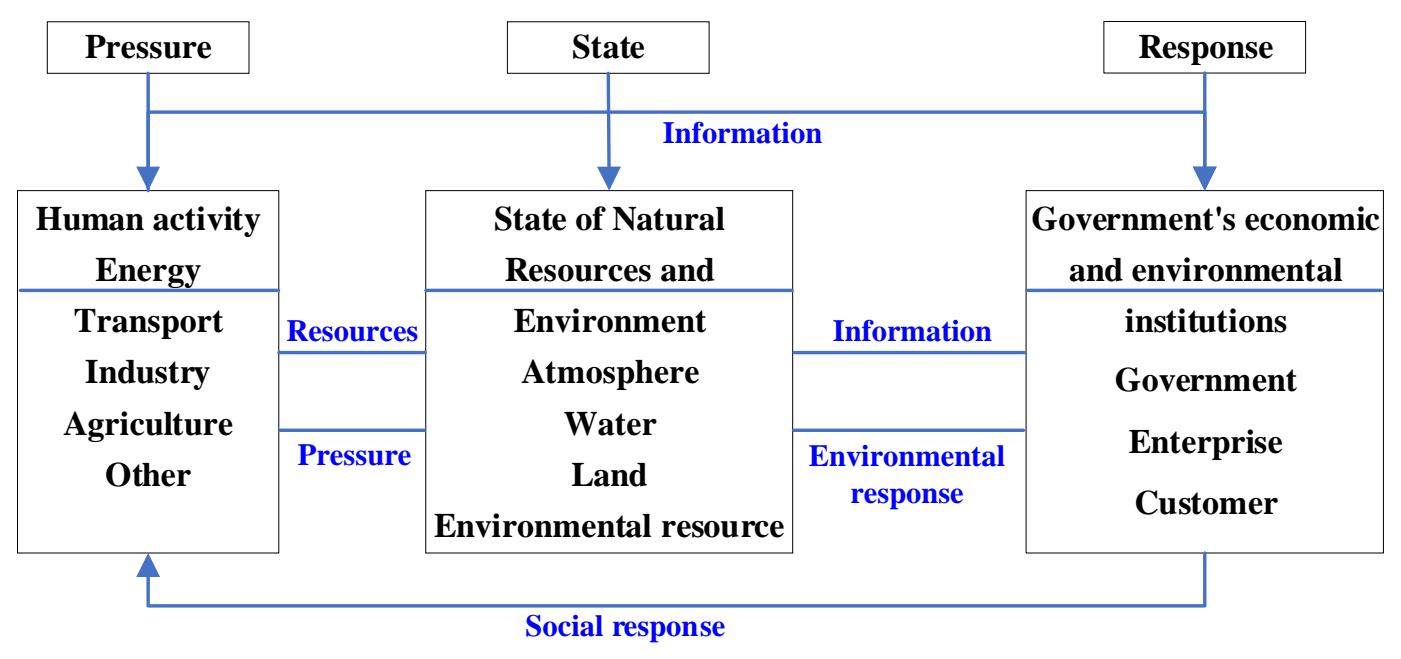

Figure 2. PSR framework

It can be further seen from Figure 2 that the PSR model contains a strong logical causality. First, it shows the degree of improvement or even deterioration for the ecoenvironment by describing the "state" of the eco-environment. Secondly, it discusses the impact degree of the eco-environment on social and economic development under the economic and social "pressure". Finally, through the "response" at the institutional and policy levels, the measures are taken for the "state" of the eco-environment.

\section{Eco-environmental impact assessment system based on PSR model}

With reference to the relevant research literature ( $\mathrm{Jr}$ et al., 2013; Prestrelo and Monteiro-Neto, 2016), the eco-environmental impact assessment indicators based on the PSR model were established, as shown in Table 1.

Table 1. Eco-environmental impact assessment indicators based on PSR model

\begin{tabular}{|c|c|c|}
\hline Target layer & Criterion layer & Indicator layer \\
\hline \multirow{3}{*}{$\begin{array}{l}\text { Eco-environmental } \\
\text { status index }\end{array}$} & Socio-economic pressure $(\mathrm{P})$ & $\begin{array}{c}\text { Per capita GDP } \\
\text { Urbanization level } \\
\text { Traffic network density }\end{array}$ \\
\hline & Ecological environment state $(\mathrm{S})$ & $\begin{array}{c}\text { Vegetation coverage } \\
\text { Plant and biodiversity } \\
\text { Water resources abundance and deficiency index }\end{array}$ \\
\hline & Policy response $(\mathrm{R})$ & $\begin{array}{l}\text { Protection index of ecologically sensitive areas } \\
\text { Indicators of land reclamation } \\
\text { Intensive utilization of rural residential areas }\end{array}$ \\
\hline
\end{tabular}

Different indicators vary in their dimensions, making it impossible to compare the indicators and to truly reflect the current relationship between the indicators. So, it is necessary to standardize the assessment indicators. When these indicators and the ecoenvironment shows a positive and negative relationship, the standardized values of indicators are expressed in Equations 1 and 2 below, respectively. The research data on 
urban planning were collected through statistical survey and published on the China Statistical Yearbook released by National Bureau of Statistics, China.

$$
\begin{gathered}
P I_{i}=\frac{X_{i}-X_{\text {min }}}{X_{\text {max }}-X_{\text {min }}} * 100 \% \\
P I_{i}=\left(1-\frac{X_{i}-X_{\text {min }}}{X_{\text {max }}-X_{\text {min }}}\right) * 100 \%
\end{gathered}
$$

where $P I_{i}$ is the normalized value of the ${ }^{i}$ th indicator, $X_{\min }$ is its minimum value, $X_{i}$ is its actual value, and $X_{\max }$ is its maximum value.

Among them, with $P I_{i}$ being closer to $100 \%$, it indicates a better eco-environment reflected by this indicator.

Furthermore, it is necessary to analyse the correlation of the indicators and screen out the highly correlated indicators, as shown in Equation 3.

$$
r=\frac{\sum(X-\bar{X}) \cdot(Y-\bar{Y})}{\sqrt{\sum(X-\bar{X})^{2} \cdot \sum(Y-\bar{Y})^{2}}}=\frac{\sum X Y-\frac{\sum X \sum Y}{n}}{\sqrt{\left[\sum X^{2}-\frac{\left(\sum X\right)^{2}}{n}\right]\left[\sum Y^{2}-\frac{\left(\sum Y\right)^{2}}{n}\right]}}
$$

where $r$ is the correlation coefficient between the indicators; $X$ and $Y$ are the normalized value of the different indicators.

$r$ is usually between -1 and +1 ; the degree of correlation between indicators is positively correlated with the absolute value of $r$.

\section{Determination of indicator weights}

Analytic Hierarchy Process (AHP) can decompose the relevant factors of the problem into three layers: goals, criteria and alternatives. As shown in Figure 3, the goal layer A lists the goal of problem solving, i.e. the overall objective of the AHP; the criterion layer $\mathrm{B}$ gives the criteria that affect the realization of the goal; the alternative layer $\mathrm{C}$ provides the various indicators that promote the achievement of the goal.

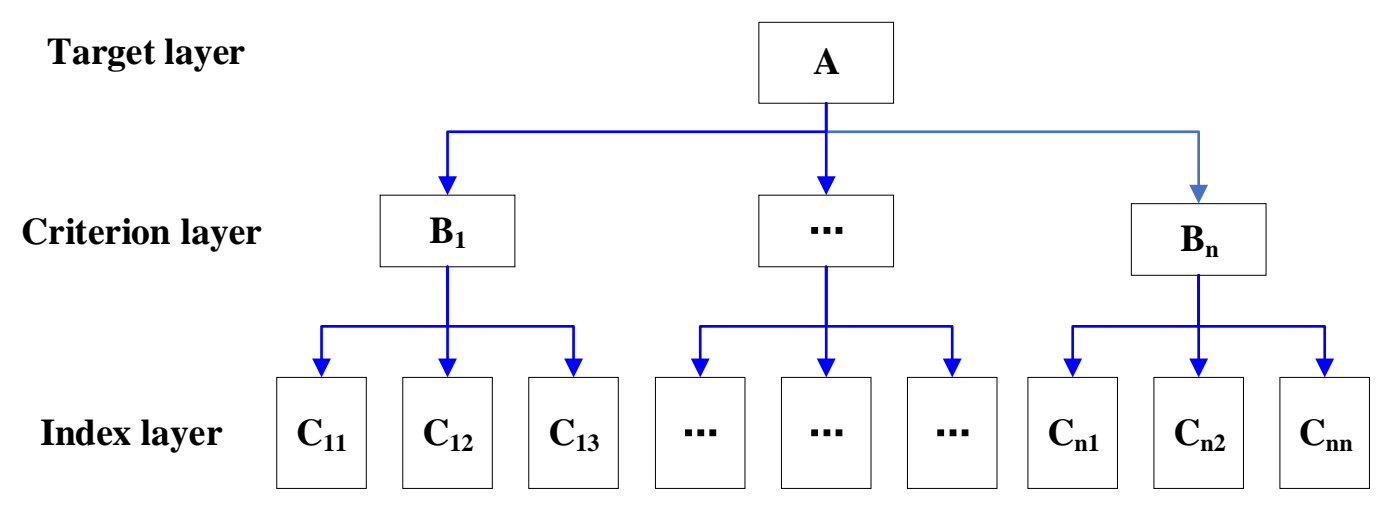

Figure 3. AHP structural model 
The AHP was used to construct a judgment matrix (Eq.4) by pairwise comparison between indicators, perform a consistency test $(E q .5)$, and then determine the weight of each indicator.

$$
\begin{gathered}
\left(\begin{array}{ccccc}
A & B_{1} & B_{2} & \ldots & B_{n} \\
B_{1} & c_{11} & c_{12} & \ldots & c_{1 n} \\
B_{2} & c_{21} & c_{22} & \ldots & c_{2 n} \\
\vdots & \vdots & \vdots & \ddots & \vdots \\
B_{n} & c_{n 1} & c_{n 2} & \ldots & c_{n n}
\end{array}\right) \\
C R=\frac{\sum_{j=1}^{m} C I(j) c_{j}}{\sum_{j=1}^{m} R I(j) c_{j}}
\end{gathered}
$$

In Equation 5, $C I$ is the consistency indicator, and $C R$ is the consistency ratio.

\section{Classification of eco-environment indicators}

The eco-environment evaluation is shown in Equation 6.

$$
E I=\sum_{i=1}^{n} w_{i} \cdot c_{i}
$$

where $w_{i}$ is the indicator weight; $c_{i}$ is the normalized value of the indicator.

Generally, the eco-environment indicators can be classified into four grades, namely excellent, good, fair, and poor, as shown in Table 2.

Table 2. Classification of eco-environment indicators

\begin{tabular}{c|c|c|c|c}
\hline Level & Excellent & Good & Commonly & Bad \\
\hline Index & $E I \geq 80$ & $60 \leq E I<80$ & $40 \leq E I \leq 60$ & $E I<40$ \\
\hline
\end{tabular}

The extent of the eco-environment changes before and after urban planning can be divided into: significant change, obvious change, slight change, and almost no change. The specific changes and the corresponding values of each level are shown in Table 3.

Table 3. Different impact degrees of urban planning on the eco-environment

\begin{tabular}{c|c|c|c|c}
\hline Level & Significant change & Obvious change & Slight change & Almost invariable \\
\hline Index & $|\Delta E I| \geq 10$ & $5 \leq|\Delta E I|<10$ & $2 \leq|\Delta E I|<5$ & $|\Delta E I|<2$ \\
\hline \multirow{1}{*}{ Description } & $\begin{array}{c}\text { The ecological } \\
\text { environment has changed } \\
\text { significantly. If } \Delta E I \text { is } \\
\text { positive, it shows a } \\
\text { significant improvement, } \\
\text { and vice versa, a } \\
\text { significant deterioration }\end{array}$ & $\begin{array}{c}\text { The ecological } \\
\text { environment has been } \\
\text { greatly changed. If } \Delta E I \\
\text { is positive, it shows a } \\
\text { marked improvement, } \\
\text { and vice versa, a marked } \\
\text { deterioration }\end{array}$ & $\begin{array}{c}\text { The ecological } \\
\text { environment has } \\
\text { changed slightly. If } \\
\Delta E I \text { is positive, it } \\
\text { means slightly better, } \\
\text { and vice versa, } \\
\text { slightly worse }\end{array}$ & $\begin{array}{c}\text { The state of } \\
\text { ecological } \\
\text { environment has } \\
\text { hardly changed }\end{array}$ \\
\hline
\end{tabular}




\section{Results}

One certain city was selected to plot the urban master plan for its three districts and six counties during the period of 2020-2040. The base data were collected from 2009 to 2018, with 2018 being the base year. The actual values of various eco-environment indicators are shown in Table 4, where B1 B6 are productivity, stability, protection, economic vitality, social acceptance, and policy response, respectively; $\mathrm{C} 1 \sim \mathrm{C} 20$ are land utilization rate, area ratio of basic farmland, ratio of non-agricultural construction land, per unit area yield of grain, diversity of land use, land development rate, land consolidation rate, land reclamation rate, farmland conversion rate, area ratio of ecological land, forest coverage, water surface index, per capita public green area in urban areas, output index of construction land, output index of agricultural land, per capita GDP, economic density, expert satisfaction, protection index of ecologically sensitive area, intensive utilization of rural residential areas.

Table 4. Actual values of various eco-environment indicators

\begin{tabular}{c|c|c|c|c|c|c|c}
\hline \multicolumn{2}{c|}{ Index/Year } & $\mathbf{2 0 1 8}$ & $\mathbf{2 0 2 0}$ & $\mathbf{2 0 2 5}$ & $\mathbf{2 0 3 0}$ & $\mathbf{2 0 3 5}$ & $\mathbf{2 0 4 0}$ \\
\hline \multirow{5}{*}{ B1 } & C1 & 0.58 & 0.70 & 1.04 & 1.39 & 2.07 & 12.99 \\
& C2 & 240 & 244 & 247 & 251 & 256 & 269 \\
& C3 & 4.22 & 4.23 & 4.26 & 4.32 & 4.53 & 5.28 \\
& C4 & 0.26 & 0.03 & 0.26 & 0.03 & 0.27 & 0.05 \\
\hline \multirow{5}{*}{ B2 } & C5 & 802 & 673 & 723 & 784 & 853 & 1118 \\
& C6 & 1296 & 1362 & 1389 & 1409 & 1847 & 2462 \\
& C7 & 76.00 & 91.89 & 80.85 & 81.85 & 94.87 & 125.24 \\
\hline \multirow{5}{*}{ B3 } & C8 & 887 & 875 & 858 & 847 & 829 & 8785 \\
& C9 & 402 & 462 & 1144 & 1084 & 1191 & 1370 \\
& C10 & 0.38 & 0.33 & 0.28 & 0.25 & 0.26 & 0.23 \\
\hline \multirow{3}{*}{ B4 } & C11 & 10.41 & 38.75 & 51.91 & 57.96 & 65.01 & 80.01 \\
& C12 & 91.07 & 91.65 & 92.44 & 101.78 & 101.01 & 102.01 \\
\hline \multirow{5}{*}{ B5 } & C13 & 30.20 & 31.63 & 33.37 & 34.63 & 35.97 & 47.45 \\
& C14 & 1.37 & 1.34 & 1.33 & 1.32 & 1.30 & 1.27 \\
& C15 & 63.75 & 72.62 & 60.82 & 83.41 & 86.01 & 92.01 \\
& C16 & 57.12 & 52.57 & 74.90 & 72.01 & 73.23 & 79.79 \\
\hline \multirow{5}{*}{ B6 } & C17 & 84.10 & 85.75 & 88.81 & 90.14 & 89.89 & 109.99 \\
& C18 & 3.44 & 4.66 & 3.87 & 5.13 & 6.01 & 9.01 \\
& C19 & 561510 & 555524 & 528519 & 527736 & 506461 & 458601 \\
& C20 & 17.42 & 21.85 & 30.50 & 40.92 & 56.07 & 291.30 \\
\hline \multirow{6}{*}{} & & & & & & & \\
\hline
\end{tabular}

Based on the PSR model, the evaluation value of the urban planning impact on the eco-environment was obtained (Fig. 4).

Figure 4 indicates the overall upward trend of the eco-environment under the influence of the urban master plan for this City from 2018 to 2040, of which 2018-2025 is a slowly rising process, which is consistent with the development trend of this city, and also the city's environmental protection facilities and economic base are in a slow development stage; from the mid-term planning of 2025 to the long-term 2035, the city's ecological situation has made a qualitative leap and reached a new level in 2040. 


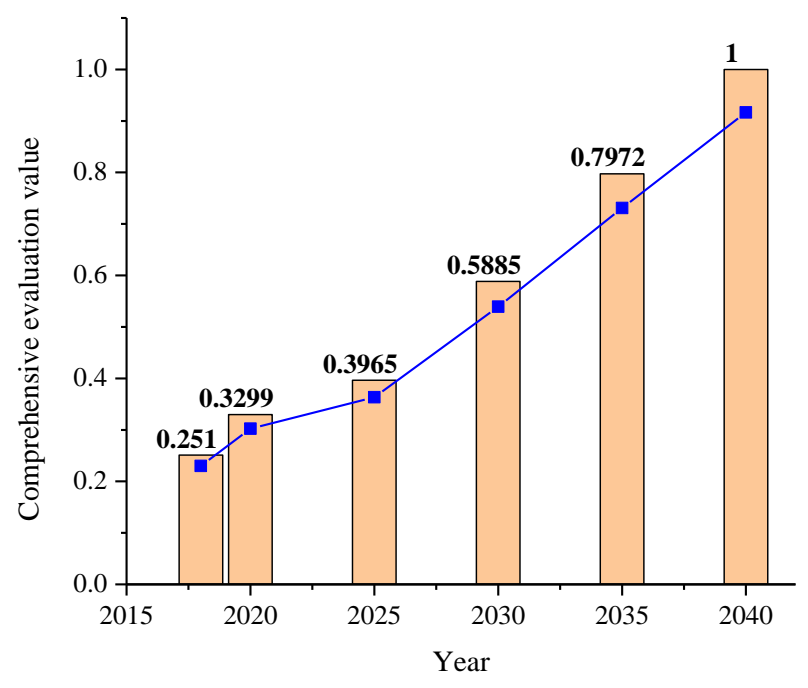

Figure 4. Evaluation value of the urban planning impact on the eco-environment for one certain city

\section{Discussion}

Figure 5 shows the variation trend of all indicators at the criterion layer from 20182040. Table 5 lists the grading levels of different indicators.

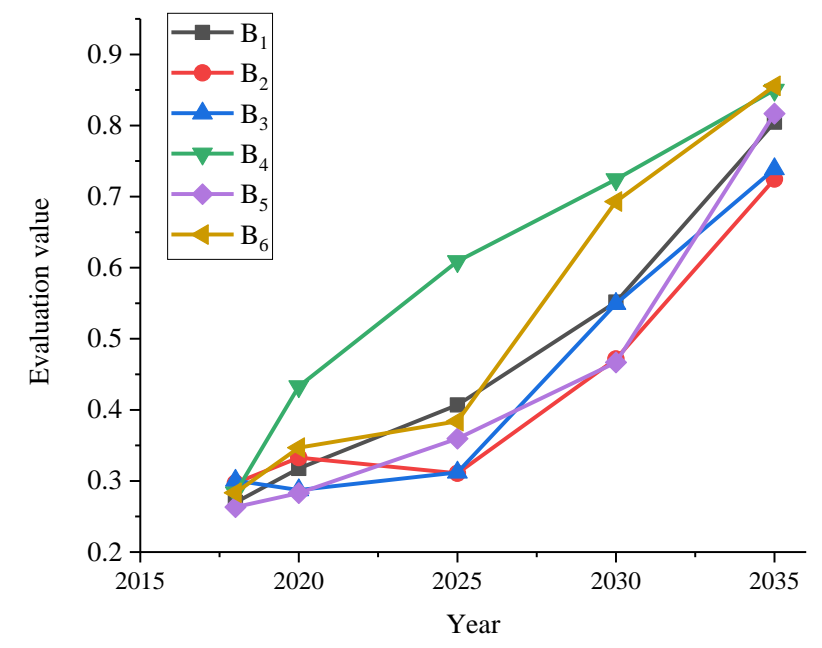

Figure 5. Variation trends of the primary indicators during the period 2018-2035

Table 5. Classification of eco-environment levels of primary indicators during the period 2018-2040

\begin{tabular}{c|c|c|c|c|c|c}
\hline Index/Year & $\mathbf{2 0 1 8}$ & $\mathbf{2 0 2 0}$ & $\mathbf{2 0 2 5}$ & $\mathbf{2 0 3 0}$ & $\mathbf{2 0 3 5}$ & $\mathbf{2 0 4 0}$ \\
\hline B1 & Relatively low & Relatively low & Secondary & Secondary & Relatively high & High \\
B2 & Relatively low & Secondary & Secondary & Relatively low & Relatively high & High \\
B3 & Relatively low & Relatively low & Relatively low & Secondary & Relatively high & Relatively high \\
B4 & Relatively low & Secondary & Secondary & Secondary & Relatively high & High \\
B5 & Relatively low & Relatively low & Secondary & Relatively high & Relatively high & High \\
B6 & Relatively low & Relatively low & Secondary & Secondary & Secondary & Relatively high \\
\hline
\end{tabular}


From the 6 primary indicators in Figure 5 and Table 5, it can be seen that all these indicators in 2018 were at a relatively low development level, but after several years of construction until 2025, most of the indicators have reached a medium level, and by 2035 it reaches a high level.

In order to accelerate the improvement of the eco-environment, it is recommended to continuously improve the internal driving force for urban development by appropriately increasing the related planned value of the indicators to economic development; to relieve the impact of urban planning on the environment, such as reducing the emissions of carbon dioxide and sulphur dioxide, control the discharge of water pollution etc.

\section{Conclusions}

This paper studies the urban planning impact assessment on the eco-environment. The main conclusions are as follows:

(1) With the purpose of realizing the urban planning impact assessment on ecoenvironment, a comprehensive analysis of the urban master planning process was conducted, and then a system diagram for this impact assessment was established.

(2) Based on the PSR model, an indicator system for impact assessment of urban planning on the eco-environment was constructed, including the goal layer, the criterion layer 1 and the alternative layer.

(3) AHP was used to determine the weight of each indicator, and evaluate the ecoenvironment of one certain city. The evaluation results show that under the current urban planning, the variation trend of eco-environment is consistent with the sustainable development of this city.

The complete eco-environmental impact assessment of urban planning should cover the predictive assessment in the preparation phase of the urban master plan, the inspective assessment in the implementation phase, and the retrospective assessment after the implementation. This paper only deals with the predictive assessment of the eco-environmental impacts of urban planning. The future research will tackle the inspective and retrospective assessments of the eco-environmental impacts of urban planning during and after the implementation of the urban master plan.

Acknowledgements. (1) Henan provincial department of science and technology key research and development and promotion special project (tackling key problems in science and technology): research on the analysis and reconstruction technology of parametric spatial texture characteristics in the development of traditional villages in central China (182102310963), 2018/01-2019/12, presided over and under research; (2) Research project of Henan science and technology think tank in 2018: research on regional feature extraction and activation path of traditional villages in central China under the background of rural revitalization (HNKJZK-2019-54b), 2019/01-2019/12, presided over and under research; (3) 2016 Zheng Zhou Institute of Light Industry doctoral research fund funded project: research on the restoration and activation strategy of traditional village texture in the area with remnants and debris-taking Henan province as an example (2016BSJJ061), 2017/01-2019/12, presided over and under research. Research project of humanities and social sciences of Henan provincial department of education, Research on the promotion of spatial features of landscape features of traditional villages in southern Henan under the protection and early warning strategy (2020-ZZJH-519). 


\section{REFERENCES}

[1] Boulay, A. M., Camillo de Camillis, J. B., Döll, P., et al. (2015): Consensus building on the development of a stress-based indicator for LCA-based impact assessment of water consumption: outcome of the expert workshops. - International Journal of Life Cycle Assessment 20(5): 577-583.

[2] Crainic, T. G., Ricciardi, N., Storchi, G. (2009): Models for evaluating and planning city logistics systems. - Transportation Science 43(4): 432-454.

[3] Elena, D., Díaz, C. M., Baquero, R. A. (2008): Effects of landscape complexity on the ecological effectiveness of agri-environment schemes. - Landscape Ecology 23(2): 135148.

[4] Fitzpatrick, P., Sinclair, A. J., Mitchell, B. (2008): Environmental impact assessment under the Mackenzie valley resource management act: deliberative democracy in Canada's north. - Environmental Management 42(1): 1-18.

[5] Jr, G. R., Kawamura, A., Medina, R., Amaguchi, H., Nakagawa, N., Bui, D. D. (2013): Environmental impact assessment of structural flood mitigation measures by a rapid impact assessment matrix (RIAM) technique: a case study in metro Manila, Philippines. Science of the Total Environment 456-457(7): 137-147.

[6] Korol, J., Burchart-Korol, D., Pichlak, M. (2016): Expansion of environmental impact assessment for eco-efficiency evaluation of biocomposites for industrial application. Journal of Cleaner Production 113(4): 144-152.

[7] Liu, X., He, B., Li, Z., Zhang, J., Wang, L., Wang, Z. (2011): Influence of land terracing on agricultural and ecological environment in the Loess Plateau regions of China. Environmental Earth Sciences 62(4): 797-807.

[8] Maj, G. (2015): Diversification and environmental impact assessment of plant biomass energy use. - Polish Journal of Environmental Studies 24(5): 2055-2061.

[9] Mancini, V., Micarelli, R., Pizziolod, G. (2010): The relational project: a goal for the ecology of city designing and planning. - Annals of the New York Academy of Sciences 879(1): 416-421.

[10] Muthu, S., Hans, J. F., Kálmán, J. (2010): Mechanism of the asymmetric sulfoxidation in the esomeprazole process: effects of the imidazole backbone for the enantioselection. Advanced Synthesis Catalysis 351(6): 903-919.

[11] Pang, B., Yang, P., Wang, Y., Kendall, A., Xie, H., Zhang, Y. (2015): Life cycle environmental impact assessment of a bridge with different strengthening schemes. International Journal of Life Cycle Assessment 20(9): 1300-1311.

[12] Prestrelo, L., Monteiro-Neto, C. (2016): Before-after environmental impact assessment of an artificial channel opening on a south-western Atlantic choked lagoon system. - Journal of Fish Biology 89(1): 735-752.

[13] Seenivasaperumal, M., Federsel, H.-J., Szabó, K. J. (2010): Mechanism of the asymmetric sulfoxidation in the esomeprazole process: effects of the imidazole backbone for the enantioselection. - Advanced Synthesis \& Catalysis 351(6): 903-919.

[14] Shiojiri, K., Yamasaki, A., Fujii, M., Kiyono, F., Yanagisawa, Y. (2010): Life cycle impact assessment of various treatment scenarios for sulfur hexafluoride (sf6) used as an insulating gas. - Environmental Progress and Sustainable Energy 25(3): 218-227.

[15] Wang, Y. S., Lou, Z. P., Sun, C. C., Sun, S. (2008): Ecological environment changes in Daya Bay, China, from 1982 to 2004. - Marine Pollution Bulletin 56(11): 1871-1879.

[16] Wolfslehner, B., Vacik, H. (2008): Evaluating sustainable forest management strategies with the analytic network process in a pressure-state-response framework. - Journal of Environmental Management 88(1): 1-10.

[17] Zhou, J., Chang, V. W. C., Fane, A. G. (2013): An improved life cycle impact assessment (lcia) approach for assessing aquatic eco-toxic impact of brine disposal from seawater desalination plants. - Desalination 308(1): 233-241. 